\title{
PENGEMBANGAN KAWASAN PERDESAAN BERBASIS AGRIBISNIS DI KECAMATAN KELIMUTU, KABUPATEN ENDE, PROPINSI NUSA TENGGARA TIMUR
}

\author{
Ernesta Leha \\ Dosen Fakultas Ekonomi Universitas Flores \\ Jl. Sam Ratulangi No.1 Ende-Flores, NTT \\ Hp : 081337967978
}

\begin{abstract}
Sector of agriculture experienced a significant growth in the national level during 2008. This lead to the betterment of the rural society or urban society. So does the Province of Nusa Tenggara Timur. The development of the sector of agriculture is significant enough but it is not quite optimal. It could be seen from the decreasing capability in absorbing manpower. This is the strong reason why rural areas need developing as agribusiness based-areas because the majority of the people who live in rural area are farmer.

Knowing the prospect of a area if developed as a agribusiness based-areas needs a specific research which can formulate priority of right strategies to develop agribusiness-based rural areas. This research was performed in the sub district of Kelimutu, regency of Ende, Province of Nusa Tenggara Timur. The internal factors which constitute the strength and the weakness are the availability of resources and land, farmer group, agricultural extension doer, cooperation, government official, human resources, socio culture, technology, management, continuity of product and irrigation. Meanwhile the external factors which constitute the chance and barrier are tourism, stakeholder cooperation, foreign people, marketing, strategic location, the emergence of new agricultural center area, transportation problems, partnership, public demand, social problems, opposition, and rivalry.

This research was used was qualitative and quantitative ones which are obtained by in-depth interview, observation, questionnaire and document analysis. Meanwhile, the method and analysis technique which were used were (1) Matrix analysis of EFAS and EFAS; (2) SWOT analysis and (3) analysis of QSPM.

From the research, formulations of alternative strategy agresive which could be applied in the village of Kelimutu are (a) To increase the quality of human resource of Kelimutu in working out agribusiness-based natural resources and land, (b) To elevate the cooperation of stakeholder in developing the sub district of Kelimutu because this area is a tourism area having a great potency of agribusiness and (c) To increase the capability of farmer management in the effort of agriculture, the processing and marketing of the agricultural stuff. Meanwhile, strategy priorities of intensive growth which could be applied are (a)Market penetration strategy to increase market share of agricultural products of the area through an extensive marketing effort, (b) Market Development Strategy which is intended to introduce agricultural product (from sub district of Kelimutu) to new areas and in global perspective, as well as the development of international-scale market and (c) Product development strategy which is intended to increase sale by improving or modifying the existing products.
\end{abstract}

Keyword : development, agribusiness, strategy, alternative, priority, partnership 


\section{PENDAHULUAN}

Secara nasional sektor pertanian mengalami pertumbuhan yang signifikan selama tahun 2008 sebesar $4,41 \%$. Selain itu berdasarkan data kemiskinan tahun 2005-2008, kesejahteraan penduduk perdesaan dan perkotaan membaik secara berkelanjutan. Berbagai hasil penelitian menunjukkan bahwa yang paling besar kontribusinya dalam penurunan jumlah penduduk miskin adalah pertumbuhan sektor pertanian. Kontribusi sektor pertanian dalam menurunkan jumlah penduduk miskin mencapai 66\%, dengan rincian $74 \%$ di perdesaan dan $55 \%$ di perkotaan. (Statistik, Indonesia, 2008)

Nusa Tenggara Timur sebagai salah satu propinsi di Kawasan Timur Indonesia memiliki gambaran kemiskinan yang hampir sama dengan potret Indonesia secara umum. Pertumbuhan ekonomi NTT memberikan sinyal positif bagi perbaikan tingkat kesejahteraan namun belum terlalu signifikan. Ada tiga indikator yang menunjukkan adanya perbaikan kesejahteraan masyarakat di propinsi ini yakni Tingkat Pengangguran Terbuka (TPT), Tingkat Kemiskinan dan Tingkat Kualitas Hidup. Pada Tahun 2008, Tingkat Pengangguran Terbuka (TPT) di Propinsi NTT sebesar 2,7 persen, terendah dalam 10 tahun terakhir dan prosentase penduduk miskin terus mengalami penurunan sejak tahun 2005 . Tingkat Kualitas Hidup yang diukur melalui angka Indeks Pembangunan Manusia (IPM) secara perlahan juga mengalami pertumbuhan, namun secara secara nasional peringkat NTT masih belum juga mengalami perubahan.

Upaya pengembangan kawasan perdesaan di Propinsi Nusa Tenggara Timur dengan pendekatan agribisnis merupakan pilihan mutlak saat ini mengingat mayoritas penduduk berada di daerah-daerah perdesaan, dan mereka umumnya hidup dari kegiatan pertanian. Program pengembangan agribisnis dapat diterapkan di Nusa Tenggara Timur khususnya di Kabupaten Ende Kecamatan Kelimutu dengan harapan bahwa agribisnis yang mampu menghasilkan produk pertanian dan kehutanan primer yang berdaya saing, meningkatkan nilai tambah bagi masyarakat pertanian dan nelayan, khususnya petani dan nelayan kecil, memperluas kesempatan kerja dan berusaha di perdesaan, mengembangkan ekonomi wilayah dan meningkatkan pertumbuhan ekonomi. Dalam hal ini, agribisnis diharapkan mampu menjadi leading sector ekonomi unggulan terutama di Kawasan Perdesaan Propinsi Nusa Tenggara Timur.

Berdasarkan latarbelakang di atas, maka dapat diformulasikan masalah yang berkaitan dengan pengembangan kawasan perdesaan berbasis agribisnis yakni Alternatif strategi apa yang dapat diterapkan untuk pengembangan kawasan perdesaan berbasis agribisnis di Kecamatan Kelimutu Kabupaten Ende serta Prioritas strategi apakah yang tepat untuk diterapkan di Kecamatan Kelimutu Kabupaten Ende. Penelitian ini bertujuan untuk merumuskan strategi alternatif pengembangan kawasan perdesaan berbasis agribisnis di Kecamatan Kelimutu Kabupaten Ende dan merumuskan prioritas strategi yang tepat untuk pengembangan kawasan perdesaan berbasis agribisnis di Kecamatan Kelimutu Kabupaten Ende.

Hasil penelitian ini diharapkan memberikan manfaat praktis yakni sebagai tambahan pemikiran dalam mengambil kebijakan yang terkait dengan pengembangan kawasan perdesaan berbasis agribisnis dan 
sebagai bahan pertimbangan bagi para stakeholders di dalam mengambil keputusan pendampingan agribisnis. Sedangkan manfaat teoritisnya adalah sebagai karya ilmiah yang dapat dijadikan dasar pijakan yang mampu memberi motivasi untuk pengamalan ilmu yang terkait dengan judul penelitian dan sebagai referensi bagi pembaca atau peneliti lain yang berkonsentrasi pada pengembangan kawasan perdesaan berbasis agribisnis.

\section{METODOLOGI PENELITIAN}

Penelitian ini merupakan penelitian survei dengan cara evaluatif formatif yang dilakukan untuk mengevaluasi faktor internal dan faktor eksternal yang mempengaruhi berhasil tidaknya praktek pengembangan agribisnis di perdesaan pada Kecamatan Kelimutu Kabupaten Ende Propinsi NTT. Jenis penelitian yang akan dilakukan adalah studi kasus dengan penelitian deskriptif kualitatif.

Dalam penelitian ini jenis data yang digunakan adalah data kualitatif dan data kuantitatif. Pengumpulan data menggunakan beberapa metode yakni metode angket, wawancara mendalam (indepth interview), observasi, analisa dokumen dan Focus Group Discussion (FGD). Populasi Penelitian adalah semua petani yang telah tergabung dalam kelompok industri kecil baik yang berada di bawah bimbingan Dinas Perindustrian dan Perdagangan Kabupaten Ende, maupun yang diasuh oleh Balai TNK dan LSM-LSM yang berkonsentrasi dalam pemberdayaan masyarakat petani. Pengambilan sampel dalam penelitian ini dilakukan dengan metode sensus sedangkan untuk penentuan responden digunakan metode purposive sampling. Metode analisis yang digunakan adalah 1) Analisis Matriks IFAS dan EFAS yang akan menghasilkan strategi umum (grand strategy); 2) Analisis SWOT dengan menggunakan diagram dan matriks SWOT, yang akan menghasilkan alternatif strategi; dan 3) Analisis QSPM yang akan menghasilkan urutan strategi mulai dari yang paling prioritas sampai yang tidak prioritas

\section{HASIL DAN PEMBAHASAN}

Dari Kegiatan Focus Group Discussion di Kecamatan Kelimutu diperoleh identifikasi faktor-faktor internal dan eksternal sebagai berikut :

A. Faktor Internal

I. Kekuatan (Strenght)

1) Ketersediaan Sumber Daya Alam yang melimpah

2) Ketersediaan Lahan Pertanian yang produktif

3) Adanya Kelompok Tani yang solid

4) Kehadiran Penyuluh Pertanian Lapangan (PPL)

5) Kesadaran Berkoperasi yang cukup tinggi

6) Aparat Desa

II Kelemahan (Weakness)

1) Kualitas Sumber Daya Manusia (SDM) yang rendah

2) Kondisi sosial budaya

3) Keterbatasan Teknologi

4) Pemahaman manajemen usaha yang rendah

5) Kontinyuitas produk yang tidak stabil

6) Sistem irigasi yang buruk

B. Faktor Eksternal

I. Peluang (Opportunities)

1) Adanya Obyek Pariwisata Danau Kelimutu

2) Kerjasama Stakeholder

3) Kehadiran Pihak Luar

4) Potensi pemasaran yang menjanjikan

5) Lokasi kecamatan yang cukup strategis 
6) Lahirnya KSP baru

II Ancaman (Threats)

1) Jalur transportasi yang tidak memadai

2) Tidak adanya jalinan kemitraan dengan pihak lain

3) Tuntutan Masyarakat

4) Kerawanan sosial

5) Kelompok oposisi

6) Makin banyaknya pesaing
A. Hasil Evaluasi Lingkungan Internal dan Eksternal Setelah identifikasi variabel internal dan variabel eksternal diketahui, langkah berikutnya adalah memberikan penilaian terhadap masing-masing indikator tersebut agar diketahui sumbangan masing-masing indikator terhadap upaya Pengembangan Kawasan Perdesaan Berbasis Agribisnis.

Tabel 1. Matrik Faktor Internal Pengembangan Kawasan Perdesaan Berbasis Agribisnis di Kecamatan Kelimutu

\begin{tabular}{|c|c|c|c|c|}
\hline Faktor-Faktor Internal & Bobot & Skala & Skor & Keterangan \\
\hline Kekuatan & & & & \multirow{7}{*}{$\begin{array}{l}\text { Dominasi SDA (sawah, tegalan, } \\
\text { pekarangan )yang digarap oleh } \\
\text { kelompok petani secara maksimal } \\
\text { akibat dari injeksi dari luar dapat } \\
\text { menjadi pendorong kegiatan } \\
\text { agribisnis ke depan. }\end{array}$} \\
\hline 1. Ketersediaan SDA & 0,15 & 4 & 0.60 & \\
\hline 2. Ketersediaan Lahan & 0,10 & 4 & 0,40 & \\
\hline 3. Adanya Kelompok Tani & 0,10 & 4 & 0,40 & \\
\hline 4. Kehadiran PPL & 0,10 & 3 & 0,30 & \\
\hline 5. Kesadaran Berkoperasi & 0,10 & 3 & 0,30 & \\
\hline 6. Aparat Desa & 0,10 & 3 & 0,30 & \\
\hline \multicolumn{5}{|l|}{ Kelemahan: } \\
\hline 1. Kualitas SDM yang rendah & 0,10 & 4 & 0,40 & \multirow{6}{*}{$\begin{array}{l}\text { Kualitas SDM dan kondisi Sosial } \\
\text { budaya sangat besar pengaruhnya } \\
\text { terhadap pengembangan kawasan } \\
\text { yang diperburuk oleh lemahnya } \\
\text { manajemen akibat rendahnya } \\
\text { pendidikan }\end{array}$} \\
\hline 2. Kondisi Sosial Budaya & 0,05 & 4 & 0,20 & \\
\hline 3. Keterbatasan Teknologi & 0,05 & 3 & 0,15 & \\
\hline 4. Pemahaman Manajemen yang rendah & 0,05 & 4 & 0,20 & \\
\hline 5. Kontinyuitas produk yang tidak stabil & 0,05 & 2 & 0,10 & \\
\hline 6. Sistem irigasi yang buruk & 0,05 & 1 & 0,05 & \\
\hline
\end{tabular}

Sumber : Diolah dari data primer

Dari pembobotan dan rating yang dilakukan pada matriks IFE di atas diketahui bahwa lima faktor internal yang berupa kekuatan memiliki skala yang hampir sama yakni 4 dan 3. Kekuatan utama terletak pada faktor Ketersediaan Sumber Daya Alam yang ditunjukkan dengan skor 0,60 dan factor Ketersediaan Lahan serta Adanya Kelompok Tani yang solid yang masing-masing ditunjukkan dengan skor 0,40 Sedangkan kelemahan utamanya terletak pada faktor Sumber Daya Manusia dan kondisi sosial budaya yang ditunjukkan dengan skor 0,40 dan 0,20. Total skor factor internal yang sebesar 3,30 termasuk dalam kategori 'kuat' karena berada di atas rata-rata 2,50 (David, 2000). Ini berarti posisi factor internal pengembangan kawasan perdesaan berbasis agribisnis di Kecamatan Kelimutu cukup kuat dalam memanfaatkan kekuatan untuk mengatasi kelemahan. 
Tabel 2 Matriks Faktor Eksternal Pengembangan Kawasan Perdesaan Berbasis Agribisnis di Kecamatan Kelimutu

\begin{tabular}{|c|c|c|c|c|}
\hline Faktor Eksternal & Bobot & Skala & Skor & Keterangan \\
\hline \multicolumn{5}{|l|}{ Peluang : } \\
\hline 1. Obyek Pariwisata Danau Kelimutu & 0,20 & 4 & 0,80 & \multirow{6}{*}{$\begin{array}{l}\text { Obyek Pariwisata Kelimutu merupakan } \\
\text { potensi pendukung utama pengembangan } \\
\text { kawasan agribisnis yang didukung oleh } \\
\text { kerjasama stakeholder, kesadaran } \\
\text { berkoperasi dan lokasi yang strategis. }\end{array}$} \\
\hline 2. Kerjasama Stakeholder & 0,10 & 4 & 0,40 & \\
\hline 3. Kehadiran Pihak Luar & 0,10 & 4 & 0,40 & \\
\hline 4. Potensi pemasaran & 0,10 & 4 & 0,40 & \\
\hline 5. Lokasi yang strategis & 0,10 & 3 & 0,30 & \\
\hline 6. Lahirnya KSP baru & 0,05 & 2 & 0,10 & \\
\hline \multicolumn{5}{|l|}{ Ancaman : } \\
\hline 1. Jalur transportasi yang tidak memadai & 0,10 & 4 & 0,40 & \multirow{6}{*}{$\begin{array}{l}\text { Jalur transportasi yang tidak memadai } \\
\text { menjadi ancaman utama yang harus segera } \\
\text { ditindaklanjuti oleh PEMDA, selain tidak } \\
\text { adanya jalinan kemitraan dan makin } \\
\text { banyaknya pesaing }\end{array}$} \\
\hline 2. Tidak adanya jalinan kemitraan & 0,05 & 3 & 0,15 & \\
\hline 3. Tuntutan Masyarakat yang tinggi & 0,05 & 2 & 0,10 & \\
\hline 4. Kerawanan sosial & 0,05 & 1 & 0,05 & \\
\hline 5. Kelompok oposisi & 0,05 & 1 & 0,05 & \\
\hline 6. Makin banyaknya pesaing & 0,05 & 2 & 0,10 & \\
\hline Total & 1,00 & & 3,25 & Cenderung Kuat \\
\hline
\end{tabular}

Sumber : Diolah dari data primer

Hasil perhitungan matriks EFAS (Tabel 2) untuk Pengembangan Kawasan Perdesaan Berbasis di Kecamatan Kelimutu menunjukkan bahwa Obyek Pariwisata Danau Kelimutu merupakan peluang utama pengembangan kawasan yang ditunjukkan dengan skor 0,80 dan ancaman utamanya terletak pada jalur transportasi yang tidak memadai yang ditunjukkan dengan skor 0,40

Total skor faktor strategi eksternal sebesar 3,25 termasuk dalam kategori "kuat" dan menurut kriteria David (2000), total skor faktor strategi eksternal tersebut tergolong tinggi karena berada di atas rata-rata 2,50. Ini menunjukkan bahwa faktor eksternal Pengembangan Kawasan Perdesaan Berbasis Agribisnis mampu memanfaatkan peluang dan menghindari ancaman.

\section{B. Matriks Internal - Eksternal} (Matrix I-E)

Dari hasil analisis matrik faktor eksternal dan internal diketahui bahwa total skor bobot faktor internal adalah 3,30 dan total skor bobot faktor eksternalnya adalah 3,25 Total skor bobot faktor internal dan eksternal tersebut menempatkan Kawasan Perdesaan di Kecamatan Kelimutu pada Sel ke I dalam rangka rangka Pengembangan Kawasan Berbasis Agribisnis sebagai berikut : 


\section{SKOR}

TOTAL BOBOT SEDANG

EFE

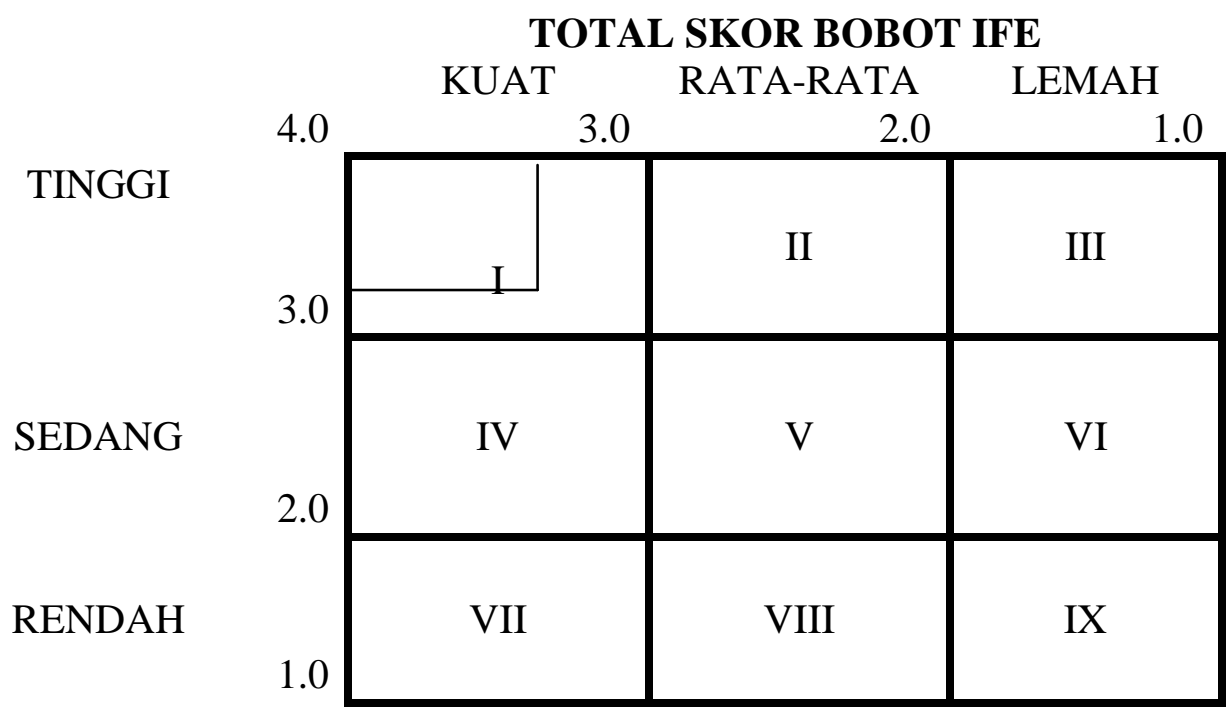

\section{Gambar 1 Matriks Internal - Eksternal (I - E) Pengembangan Kawasan Perdesaan Berbasis Agribisnis di Kecamatan Kelimutu Kabupaten Ende}

Dari diagram tersebut terlihat bahwa posisi Kecamatan Kelimutu dalam rangka Pengembangan Kawasan Perdesaan Berbasis Agribisnis berada pada SEL I yang berarti strategi sesuai dengan sel tersebut adalah strategi pertumbuhan (growth strategy).

C. Analisis SWOT Pengembangan Kawasan Perdesaan Berbasis Agribisnis

\section{di Kecamatan Kelimutu}

Berdasarkan hasil penelitian pada masing-masing indikator dalam matrik internal dan eksternal memberikan gambaran posisi kawasan perdesaan pada diagram analisa $\quad$ SWOT, yang mencerminkan arah perkembangan (grand strategy) pertumbuhan desa.

Posisi kawasan berdasarkan faktor internal digambarkan pada garis datar/absis $=(21: 6)-(18:$ $6)=3,50-3,0=0,50$ (garis tegak positif). Sedangkan posisi berdasarkan faktor eksternal digambarkan pada garis tegak/ordinat $=(21: 6)-(13: 6)$ $=3,50-2,17=1,33$ (garis vektor positif). Titik temu antar kedua vector terletak pada ordinat $(0,67$ : 1,33 ) yang berarti ada pada kuadran I ( strategi agresif ) yang dapat digambarkan sbb : 


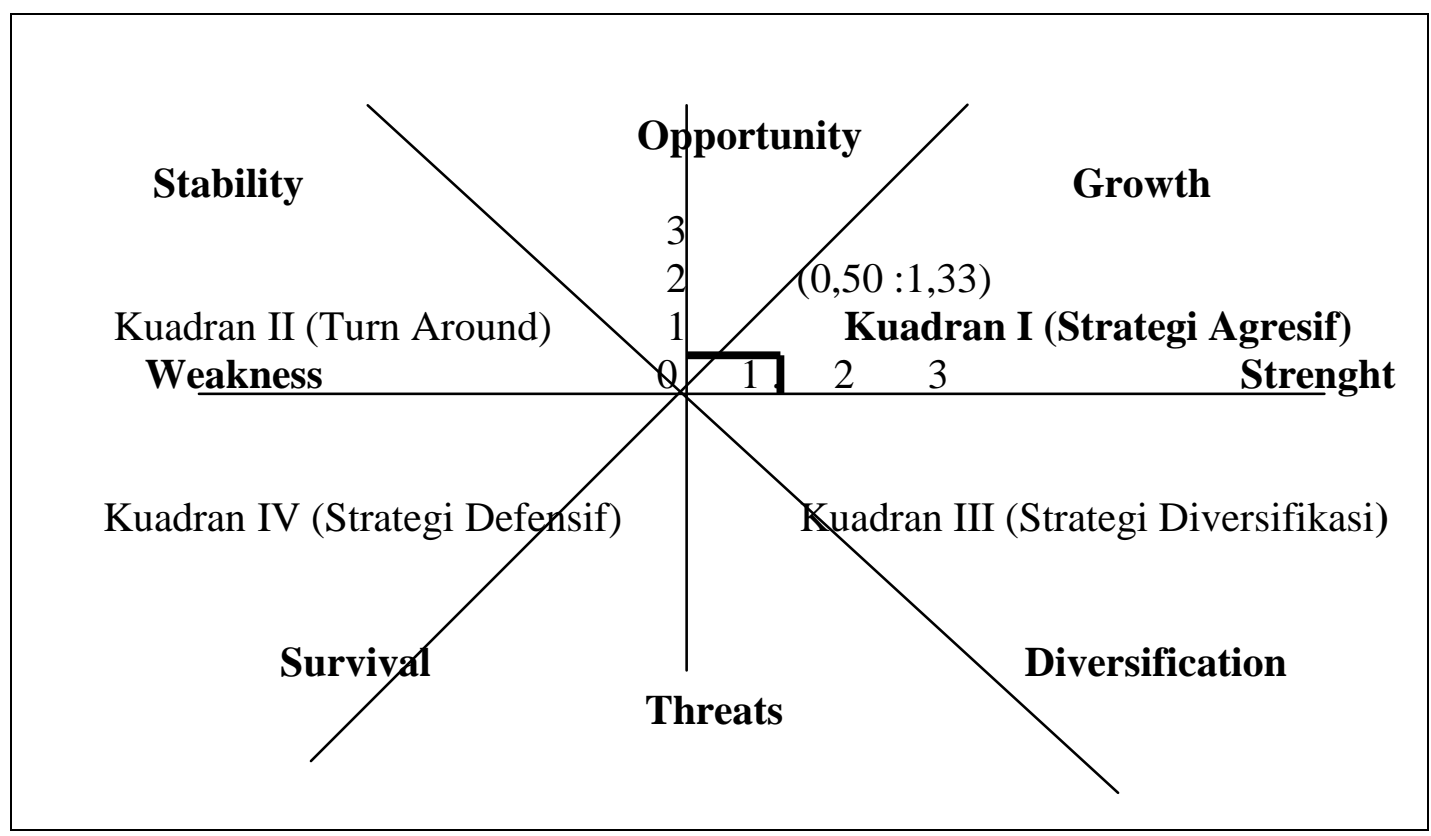

Gambar 2 Diagram SWOT pada posisi Growth

Setelah diagram SWOT terbentuk kemudian dibuat matriks SWOT yang menjelaskan berbagai alternatif yang penting untuk membantu pengembangan empat tipe strategi yaitu Strategi SO, WO, ST dan WT. Matriks SWOTnya dapat dilihat Tabel 3 sebagai berikut : 


\section{Tabel 3. Strategi Operasional Kecamatan Kelimutu Sebagai Kawasan Berbasis Agribisnis}

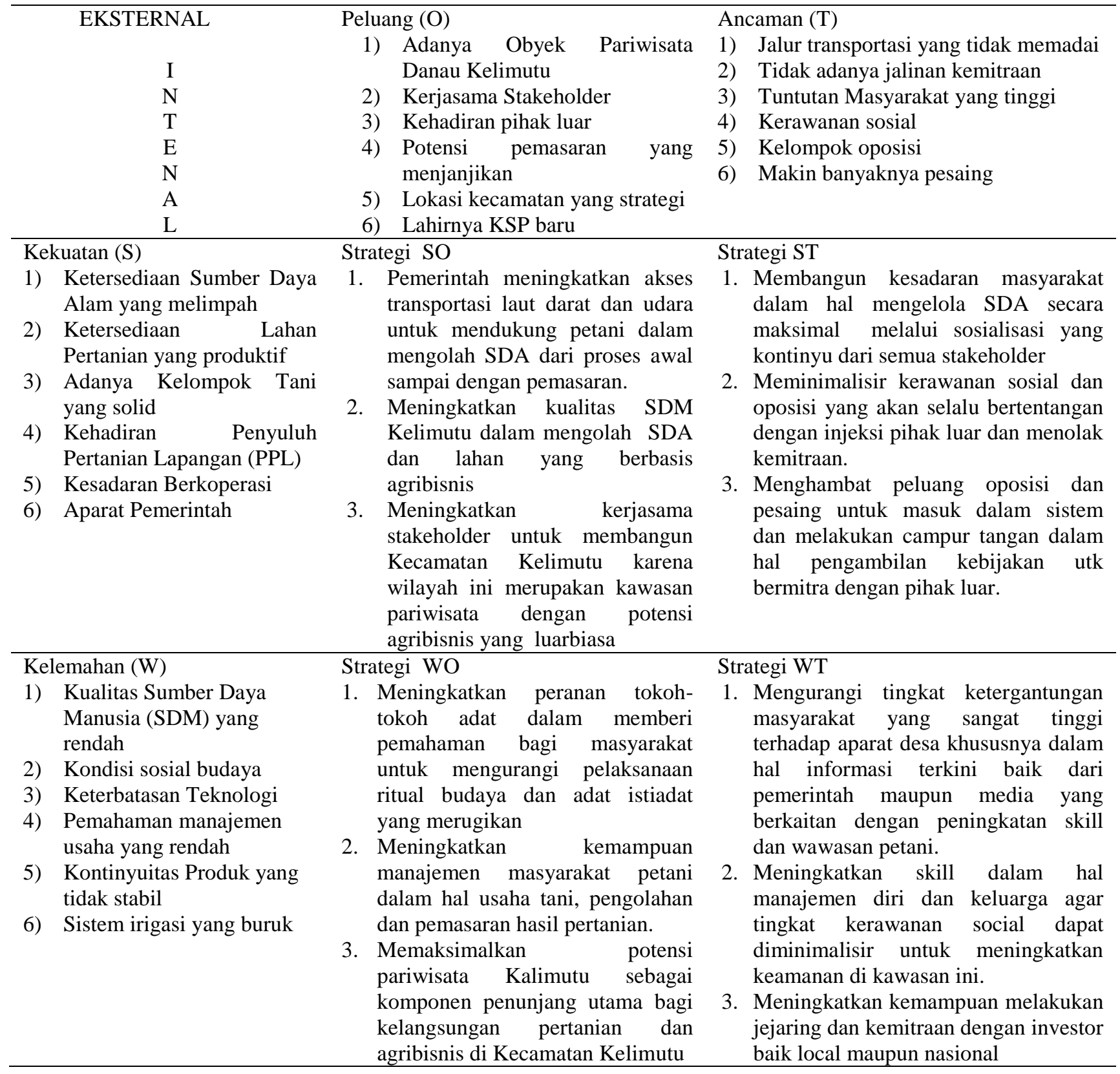


Berdasarkan Tabel 3 di atas maka disusun alternatif strategi sebagai berikut :

Tabel 4 Alternatif Strategi Berdasarkan Peringkat

\begin{tabular}{|c|c|c|c|c|c|}
\hline No & Alternatif Strategi & Kombinasi Variabel & Kode & Skor & Peringkat \\
\hline 1 & $\begin{array}{l}\text { Pemerintah meningkatkan akses transportasi laut } \\
\text { darat dan udara untuk mendukung petani dalam } \\
\text { menggolah SDA dari proses awal sampai dengan } \\
\text { pemasaran }\end{array}$ & $\mathrm{S} 1+\mathrm{S} 5+\mathrm{O} 1+\mathrm{O} 3+\mathrm{O} 5$ & SO1 & 0,60 & 5 \\
\hline 2 & $\begin{array}{l}\text { Meningkatkan kualitas SDM Kelimutu dalam } \\
\text { mengolah SDA dan lahan yang berbasis agribisnis }\end{array}$ & $\mathrm{S} 1+\mathrm{S} 2+\mathrm{S} 3+\mathrm{S} 4+\mathrm{S} 5+\mathrm{O} 1+\mathrm{O} 2+\mathrm{O} 5$ & $\mathrm{SO} 2$ & 0,90 & 1 \\
\hline 3 & $\begin{array}{l}\text { Meningkatkan kerjasama stakeholder untuk } \\
\text { membangun Kecamatan Kelimutu karena wilayah } \\
\text { ini merupakan kawasan pariwisata dengan potensi } \\
\text { agribisnis yang luarbiasa }\end{array}$ & $\mathrm{S} 3+\mathrm{S} 4+\mathrm{S} 5+\mathrm{S} 6+\mathrm{O} 1+\mathrm{O} 2+\mathrm{O} 4+\mathrm{O} 6$ & $\mathrm{SO} 3$ & 0,80 & 2 \\
\hline 4 & $\begin{array}{l}\text { Membangun kesadaran masyarakat dalam hal } \\
\text { mengelola SDA secara maksimal melalui } \\
\text { sosialisasi yang kontinyu dari semua stakeholder }\end{array}$ & $\mathrm{S} 1+\mathrm{S} 3+\mathrm{S} 4+\mathrm{S} 5+\mathrm{S} 6+\mathrm{T} 2+\mathrm{T} 4++\mathrm{T} 6$ & ST1 & 0,70 & 4 \\
\hline 5 & $\begin{array}{l}\text { Meminimalisir kerawanan sosial dan oposisi yang } \\
\text { akan selalu bertentangan dengan injeksi pihak luar } \\
\text { dan menolak kemitraan. }\end{array}$ & $\mathrm{S} 3+\mathrm{S} 4+\mathrm{S} 5+\mathrm{S} 6+\mathrm{T} 3+\mathrm{T} 4+\mathrm{T} 5$ & ST2 & 0,50 & 6 \\
\hline 6 & $\begin{array}{l}\text { Menghambat peluang oposisi dan pesaing untuk } \\
\text { masuk dalam sistem dan melakukan campur tangan } \\
\text { dalam hal pengambilan kebijakan utk bermitra } \\
\text { dengan pihak luar }\end{array}$ & $\mathrm{S} 3+\mathrm{S} 4+\mathrm{S} 5+\mathrm{T} 5+\mathrm{T} 6$ & ST3 & 0,30 & 8 \\
\hline 7 & $\begin{array}{l}\text { Meningkatkan peranan tokoh-tokoh adat dalam } \\
\text { memberi pemahaman bagi masyarakat untuk } \\
\text { mengurangi pelaksanaan ritual budaya dan adat } \\
\text { istiadat yang merugikan }\end{array}$ & $\mathrm{W} 1+\mathrm{W} 2+\mathrm{O} 1+\mathrm{O} 2+\mathrm{O} 4+\mathrm{O} 5$ & WO1 & 0,65 & 5 \\
\hline 8 & $\begin{array}{l}\text { Meningkatkan kemampuan manajemen masyarakat } \\
\text { petani dalam hal usaha tani, pengolahan dan } \\
\text { pemasaran hasil pertanian }\end{array}$ & $\mathrm{W} 1+\mathrm{W} 2+\mathrm{W} 4+\mathrm{W} 5+\mathrm{O} 1+\mathrm{O} 2+\mathrm{O} 4+\mathrm{O} 5$ & WO2 & 0,75 & 3 \\
\hline 9 & $\begin{array}{l}\text { Memaksimalkan potensi pariwisata Kalimutu } \\
\text { sebagai komponen penunjang utama bagi } \\
\text { kelangsungan pertanian dan agribisnis di } \\
\text { Kecamatan Kelimutu }\end{array}$ & $\mathrm{W} 1+\mathrm{W} 2+\mathrm{W} 5+\mathrm{O} 1+\mathrm{O} 2+\mathrm{O} 5$ & WO3 & 0,60 & 6 \\
\hline 10 & $\begin{array}{l}\text { Mengurangi tingkat ketergantungan masyarakat } \\
\text { yang sangat tinggi terhadap aparat desa khususnya } \\
\text { dalam hal informasi terkini baik dari pemerintah } \\
\text { maupun media yang berkaitan dengan peningkatan } \\
\text { skill dan wawasan petani }\end{array}$ & $\mathrm{W} 1+\mathrm{W} 2+\mathrm{T} 3+\mathrm{T} 4$ & WT1 & 0,25 & 9 \\
\hline 11 & $\begin{array}{l}\text { Meningkatkan skill dalam hal manajemen diri dan } \\
\text { keluarga agar tingkat kerawanan social dapat } \\
\text { diminimalisir untuk meningkatkan keamanan di } \\
\text { kawasan ini. }\end{array}$ & $\mathrm{W} 1+\mathrm{W} 2+\mathrm{T} 4+\mathrm{T} 5$ & WT2 & 0,25 & 9 \\
\hline 12 & $\begin{array}{l}\text { Meningkatkan kemampuan melakukan jejaring dan } \\
\text { kemitraan dengan investor baik local maupun } \\
\text { nasional }\end{array}$ & $\mathrm{W} 1+\mathrm{W} 3+\mathrm{W} 4+\mathrm{W} 5+\mathrm{W} 6+\mathrm{T} 4+\mathrm{T} 5$ & WT3 & 0,45 & 7 \\
\hline
\end{tabular}

Dari hasil kombinasi factor internal dan eksternal kemudian disusun 12 strategi yang dimungkinkan menjadi alternatif strategi bagi pengembangan kawasan berbasis agribisnis di Kecamatan Kelimutu Kabupaten Ende Propinsi Nusa Tenggara Timur seperti terdapat pada Tabel 4 sebagai berikut :

\section{Strategi Strenght - Opportunities (SO)}

a) Pemerintah meningkatkan kualitas infrastruktur pendukung transportasi laut darat dan udara untuk mendukung petani dalam proses distribusi hasil-hasil pertanian dan industri di Kecamatan Kelimutu. putusnya jalur transportasi karena longsor.

b) Meningkatkan kualitas Sumber Daya Manusia dalam menggarap Sumber Daya Alam dan Lahan di Kecamatan Kelimutu dengan 
menjalin kemitraan dengan pemerintah seperti Balai TNK dan stakeholder seperti Perguruan Tinggi dan LSM-LSM baik local maupun asing.

c) Meningkatkan kerjasama stakeholder untuk membangun Kecamatan Kelimutu mengingat wilayah ini merupakan kawasan pariwisata sehingga banyak pihak berkepentingan dengan wilayah ini

II. Strategi Strenght-Threats (ST)

a) Membangun kesadaran masyarakat dalam hal mengelola SDA secara maksimal melalui sosialisasi yang kontinyu dari semua stakeholder. Tuntutan masyarakat di Kecamatan Kelimutu cukup tinggi terutama dalam hal kelengkapan infrastruktur dan injeksi modal yang terus menerus.

b) Meminimalisir kerawanan sosial dan oposisi yang akan selalu bertentangan dengan bantuan pihak luar dan menolak kemitraan.

c) Mengendalikan peluang oposisi untuk lebih bijak mengkritisi setiap bentuk pengambilan kebijakan oleh pemerintah untuk bermitra dengan pihak luar.

III. Strategi WeaknessesOpportunities (WO)

a) Meningkatkan peranan tokoh-tokoh adat dalam memberi pemahaman bagi masyarakat untuk mengurangi pelaksanaan ritual budaya dan adat istiadat yang merugikan. b) Meningkatkan kemampuan manajemen masyarakat petani dalam hal usaha tani, pengolahan dan pemasaran hasil pertanian.

c) Memaksimalkan potensi pariwisata Kalimutu sebagai komponen penunjang utama bagi kelangsungan pertanian dan agribisnis di Kecamatan Kelimutu. ini.

\section{Strategi Weaknesses-Threats} (WT)

a) Mengurangi tingkat ketergantungan masyarakat yang sangat tinggi terhadap aparat desa khususnya dalam hal informasi terkini baik dari pemerintah maupun media yang berkaitan dengan peningkatan skill dan wawasan petani.

b) Meningkatkan skill dalam hal manajemen diri dan keluarga agar tingkat kerawanan sosial dapat diminimalisir untuk meningkatkan keamanan di kawasan ini.

c) Meningkatkan kemampuan melakukan jejaring dan kemitraan dengan investor baik local maupun nasional.

Setelah melalui tahap skoring terhadap 12 alternatif strategi tersebut (Tabel 4), dipilih tiga alternatif strategi yang memiliki skor tertinggi berdasarkan evaluasi kombinasi variabel yang dapat menjadi rekomendasi utama bagi pengembangan kawasan perdesaan berbasis agribisnis di Kecamatan Kelimutu sebagai berikut 
Tabel 5 Strategy Agresif Berdasarkan Peringkat

\begin{tabular}{|c|c|c|c|}
\hline Peringkat Strategi & Uraian & Kode & Skor \\
\hline I & $\begin{array}{l}\text { Meningkatkan kualitas SDM Kelimutu dalam } \\
\text { mengolah SDA dan lahan yang berbasis } \\
\text { agribisnis }\end{array}$ & $\mathrm{SO} 2$ & 0,90 \\
\hline II & $\begin{array}{l}\text { Meningkatkan kerjasama stakeholder untuk } \\
\text { membangun Kecamatan Kelimutu karena } \\
\text { wilayah ini merupakan kawasan pariwisata } \\
\text { dengan potensi agribisnis yang luarbiasa }\end{array}$ & $\mathrm{SO} 3$ & 0,80 \\
\hline III & $\begin{array}{l}\text { Meningkatkan kemampuan manajemen } \\
\text { masyarakat petani dalam hal usaha tani, } \\
\text { pengolahan dan pemasaran hasil pertanian }\end{array}$ & WO2 & 0,75 \\
\hline
\end{tabular}

Hasil scoring alternatif strategi di atas yang menetapkan tiga strategi tersebut sebagai strategi utama juga didukung oleh hasil analisis perumusan alternatif strategi dengan metode SWOT yang berada pada kuadran I, yang berarti bahwa ketiga strategi tersebut merupakan strategi agresif sekaligus sebagai grand strategy bagi pertumbuhan Kecamatan Kelimutu sebagai Kawasan Perdesaan Berbasis Agribisnis.

D. Analisis QSPM Faktor Internal dan Eksternal di Kecamatan Kelimutu

Dari hasil analisis Matriks SWOT dihasilkan strategi alternatif yakni Strategi Agresif yang mencakup strategi intensif, intergrasi, dan diversifikasi. Ketiga alternative strategi yang direkomendasikan ini akan dianalisis lebih lanjut dengan analisis QSPM. Secara konseptual matrikas QSPM bertujuan untuk menetapkan ketertarikan relative (Relative Attractiveness) dari ketiga strategi yang telah dipilih untuk menentukan strategi mana yang paling baik untuk diimplementasikan. Attractiveness Score pada setiap strategi akan dianalisis dengan kriteria nilai 1 adalah tidak menarik sampai dengan nilai 4 adalah sangat menarik. Strategi yang mendapat Total Atractiveness Score (TAS) tertinggi merupakan strategi yang paling baik untuk diimplementasikan. 
Tabel 6 Matriks QSPM Kecamatan Kelimutu Kabupaten Ende

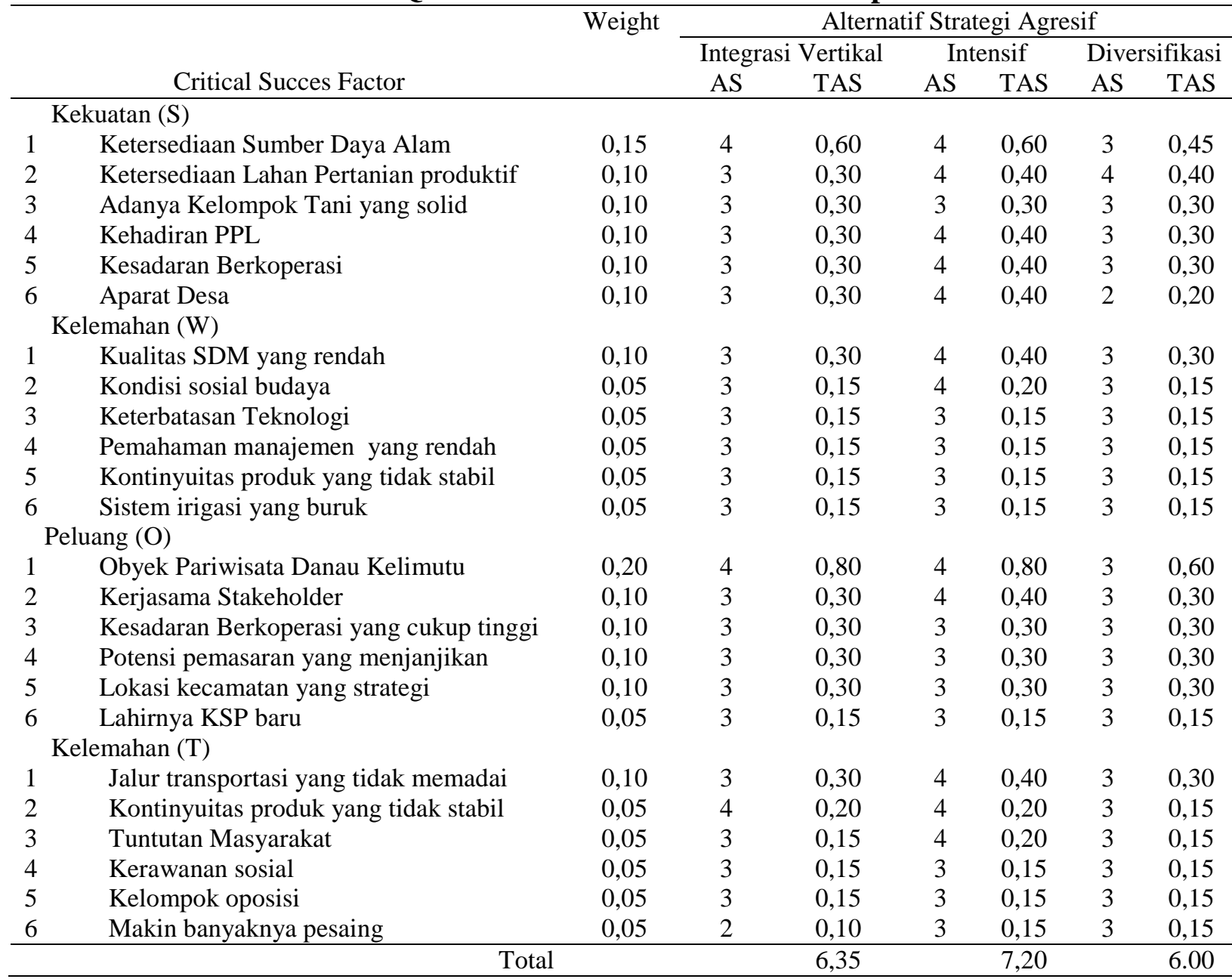

Sumber : Data Primer (diolah)

Dari analisis Decision Stage dengan menggunakan pendekatan Quantitative Strategic Planning Matrix (QSPM) pada Tabel di atas diperoleh strategic alternative dengan Total Attractiveness Score (TAS) yakni untuk Strategi Pertumbuhan Intensif sebesar 7,20, Pertumbuhan Integrasi sebesar 6,35 dan Pertumbuhan Diversifikasi sebesar 6,00

Berdasarkan analisis strategi dengan QSPM diperoleh beberapa pilihan strategi prioritas sebagai berikut

\section{A. Strategi Agresif Intensif}

Ada tiga kelompok yang masuk dalam strategi intensif ini yakni adalah strategi penetrasi pasar (market penetration), pengembangan pasar (market development) dan pengembangan produk (product development). Dikatakan strategi intensif karena dalam implementasinya memerlukan usaha-usaha intensif untuk meningkatkan posisi persaingan kawasan melalui produk yang ada. Ketiga strategi agresif intensif ini dapat dipaparkan sebagai berikut :

1) Market Penetration Strategy

Strategi ini bertujuan meningkatkan market share produkproduk pertanian kawasan melalui usaha pemasaran yang lebih luas. Konsep ini dapat diimplementasikan secara terpisah maupun berkelompok dengan strategi lain untuk dapat menambah jumlah tenaga penjual, biaya iklan, unit produk untuk promosi 
penjualan dan atau usaha promosi lainnya. Strategi ini bertujuan untuk memperluas pangsa pasar dengan kegiatan pemasaran yang optimal dan bisa dilakukan dalam kondisi pasar yang jenuh, pangsa pasar pesaing menurun dan kemampuan untuk bersaing yang meningkat.

2) Market Development Strategy

Tujuan utama dari strategi ini adalah memperkenalkan produk-produk pertanian (dari Kecamatan Kelimutu) ke daerah-daerah yang secara geografis merupakan daerah baru, dan juga dalam perspektif global, pengembangan pasar berskala internasional. Tujuan lain strategi adalah untuk meningkatkan atau memperbesar pangsa pasar. Hal ini dapat dilakukan jika Kawasan telah memiliki jaringan distribusi pendapatan laba yang sesuai dan masih ada peluang munculnya pasar baru.

3) Product Development Strategy

Strategi ini bertujuan untuk meningkatkan penjualan dengan cara meningkatkan atau memodifikasi produk-produk yang ada. Dalam kaitan dengan Pengembangan Kawasan Berbasis Agribisnis maka produk pertanian harus diolah menjadi produk agribisnis sesuai dengan kebutuhan pasar. Untuk itu, perlu adanya penelitian lanjutan untuk mengetahui kondisi riil di pasar karena semakin banyaknya pesaing yang menawarkan produk agribisnis dari daerah-daerah lain seperti Nusa Tenggara Barat, Bali dan Pulau Jawa.

\section{B. Strategi Agresif Intensif yang mencakup strategi integrasi ke depan, ke belakang dan horizontal}

1) Strategi Integrasi $\mathrm{Ke}$ Depan (Forward Integration Strategy)

Tujuannya adalah agar Kawasan mempunyai kemampuan yang besar terhadap pengendalian para distributor, agen atau pengecernya bila perlu dengan memilikinya. Hal ini dapat dilakukan jika perusahaan mendapatkan banyak masalah dengan pendistribusian barang atau jasa sehingga mengganggu stabilitas produksi padahal seharusnya Kawasan tersebut memiliki sumber daya yang cukup banyak.

2) Strategi Integrasi $\mathrm{Ke}$ Belakang (Backward Integration Strategy)

Strategi ini berupa pengawasan terhadap bahan baku agar dapat lebih ditingkatkan terutama jika para pemasok sudah dinilai tidak lagi menguntungkan bagi perusahaan seperti keterlambatan pengadaan bahan baku, kualitas bahan baku yang menurun, biaya yang meningkat sehingga tidak lagi dapat diandalkan. Tujuan strategi ini untuk mendapatkan kepemilikan dan atau meningkatkan pengendalian bagi para pemasok. Hal ini akan mudah dilakukan jika : (1) Jumlah Pemasok sedikit dan pesaingnya baik; (2) Pasokan selama ini berjalan lancar; (3) Harga produk stabil; (4) Perusahaan mempunyai modal dan sumber daya yang berkualitas.

3) Strategi Integrasi Horisontal (Horizontal Integration Strategy)

Strategi ini dimaksudkan agar perusahaan meningkatkan pengawasan terhadap para pesaing walau harus dengan memilikinya. Tujuan strategi inmi adalah untuk mendapatkan kepemilikan dan atau meningkatkan pengendalian para pesaing. Hal ini dapat dilakukan jika perusahaan memiliki posisi monopoli seizin pemerintah serta modal dan sumber daya yang dimiliki perusahaan mampu melakukan ekspansi. Jadi ketiga strategi ini secara kolektif sering dianggap sebagai strategi integrasi vertical (Vertical Integrastion Strategies) 


\section{Strategi Agresif Diversifikasi (agresive Diversification Strategies)}

Strategi diversifikasi yang mungkin dilaksanakan oleh perusahaanperusahaan yang bergerak di bidang agribisnis di Kecamatan Kelimutu adalah Strategi Diversifikasi Concentric. Strategi ini dapat dilaksanakan dengan cara menambah produk dan jasa yang baru tetapi masih saling berhubungan untuk pasar yang sama. Dalam kaitan dengan strategi ini, PEMDA Kabupaten Ende dapat bekerjasama dengan seluruh instansi terkait, investor dan stakeholder yang ada untuk melaksanakan sistem perdagangan produk pertanian dan agribisnis secara langsung pada konsumen, misalnya membuka countercounter agribisnis di tempat-tempat umum seperti Bandara, Pelabuhan, dan Lokasi Pariwisata.

Dari analisis QSPM diketahui bahwa alternatif strategi yang tepat dan implikasinya dapat segera diterapkan di Kecamatan Kelimutu adalah Strategi Agresif Intensif karena nilai Total Attractiveness Score (TAS) adalah yang terbesar dan paling tinggi yakni 7,20. Ini berarti Strategi Intensif akan menjadi Prioritas Strategi bagi Pengembangan Kecamatan Kelimutu Sebagai Kawasan Pedesaan Berbasis Agribisnis.

\section{SIMPULAN}

Berdasarkan hasil analisis data potensi internal dan eksternal yang ada di Kecamatan Kelimutu dapat disimpulkan bahwa Kecamatan ini memiliki peluang dan prospek yang sangat baik untuk dikembangkan menjadi Kawasan Perdesaan Berbasis Agribisnis dengan alternatif strategi dan prioritas strategi yang dapat diterapkan adalah Strategi Agresif dan Strategi Pertumbuhan Intensif.

1) Rumusan Alternatif Strategy Agresif yang dapat diterapkan di Kecamatan Kelimutu dalam rangka pengembangan kawasan perdesaan berbasis agribisnis adalah :

a) Meningkatkan kualitas SDM Kelimutu dalam mengolah SDA dan lahan yang berbasis agribisnis

b) Meningkatkan kerjasama stakeholder untuk membangun Kecamatan Kelimutu karena wilayah ini merupakan kawasan pariwisata dengan potensi agribisnis yang luar biasa

c) Meningkatkan kemampuan manajemen masyarakat petani dalam hal usaha tani, pengolahan dan pemasaran hasil pertanian

2) Prioritas Strategi Pertumbuhan Intensif sebagai berikut yang dapat diaplikasikan di Kecamatan Kelimutu dalam rangka pengembangan kawasan berbasis agribisnis adalah :

a) Market Penetration Strategy untuk meningkatkan market share produk-produk pertanian kawasan melalui usaha pemasaran yang lebih luas.

b) Market Development Strategy yang bertujuan untuk memperkenalkan produk-produk pertanian (dari Kecamatan Kelimutu) ke daerah-daerah yang secara geografis merupakan daerah baru, dan juga dalam perspektif global untuk pengembangan pasar berskala internasional.

c) Product Development Strategy untuk meningkatkan penjualan dengan cara meningkatkan atau memodifikasi produk-produk yang ada. 
UCAPAN TERIMA KASIH

Pada kesempatan ini penulis ingin mengucapkan terima kasih kepada semua pihak yang telah membantu dengan caranya masing-masing dalam melengkapi tulisan ini.

\section{DAFTAR PUSTAKA}

Adjid, 1998, Bunga Rampai Agribisnis Menuju Abad 21, Surat Kabar Sinar Tani.

BPS Kabupaten Ende, Peraturan Pemerintah Kabupaten Ende No : 12 Tahun 2000 Tentang Pola Dasar Pembangunan Daerah Kabupaten Ende Tahun

BPS, NTT Dalam Angka, 2008

BPS Kabupaten Ende, Ende Dalam Angka, 2008

Departemen Pertanian, 1998, Kebijakan Pokok dan Program
Pembangunan Pertanian
T.A.1999/2000. Jakarta

David, R. Fred, 2000. "Manajemen Strategi”. Jakarta: PT. Prendhalilindo

Dudung, 2001, Penyuluhan Pertanian, Yayasan Pengembang Sinar Tani, Jakarta.

Fredy Rangkuti, 2002, Analisis SWOT Teknik Membedah Kasus Bisnis, PT. Gramedia Utama, Jakarta.

Kotler, P. 1996. Manajemen Pemasaran, Analisis, Perencanaan, Implementasi, dan Pengendalian, Jakarta, Edisi Bahasa Indonesia, Terjemahan Jaka Warsana. Penerbit Erlangga.

Sadjad, 2002, Agribisnis Yang Membumi, Penerbit Grasindo, Jakarta.

Said, 2001, Manajemen Teknologi Agribisnis, Penerbit Ghalilia Indonesia.

Saragih, 2000, Suara Dari Bogor "Membangun

Sistem
Agribisnis", Departemen

Pertanian dan Kehutanan RI.

Soehoed, 2002, Bunga Rampai Pembangunan, Puri Fajar Mandiri dan Fakultas Teknik, Universitas Indonesia.

Siagian P. Sondang, 2004, Manajemen Stratejik, Bumi Aksara, Jakarta

Mardikanto, T. 1996. Penyuluhan Pembangunan Kehutanan. Departemen Kehutanan. Jakarta.

Nawawi, Hadari, 2000, Manajemen Stratejik Organisasi Non Profit Di bidang Pemerintahan dengan Ilustrasi Di Bidang Pendidikan, Gadjah Mada University Press, Yogyakarta.

Umar, Husein. 2004, Strategic Management In Action, Gramedia, Jakarta.

Van Dusseldorf, 2002, Pembangunan dan Pengembangan Desa Terpadu, Usaha Nasional, Surabaya 